\title{
Robotic cardiac surgery: Time told!
}

Francis Robicsek, MD, PhD*

From the Department of Thoracic and Cardiovascular Surgery Carolinas Heart Institute, Carolinas Medical Center and Heineman Medical Research Laboratories, Charlotte, North Carolina.

Received for publication March 27, 2007; accepted for publication May 22, 2007.

Address for reprints: Francis Robicsek, MD, PhD, 1001 Blythe Blvd, Suite 300, Charlotte, NC 28203 (E-mail: Francis.Robicsek@ carolinashealthcare.org).

J Thorac Cardiovasc Surg 2008;135:243-6

0022-5223/\$34.00

Copyright (C) 2008 by The American Association for Thoracic Surgery

doi:10.1016/j.jtcvs.2007.05.072
I do not see a widespread use of (robotics) in cardiac surgery in the future because most cases are really way too complex, and many surgeons should learn to do the simple video-assisted surgery with the same quality avoiding the high cost of robotic technology.

Friedrich Wilhelm Mohr, MD, PhD, personal communication, 2006

Assimilation of this (robotic) technology by cardiac programs has been slow. ${ }^{1}$

Evelio Rodriguez, MD, and W. Randolph Chitwood, Jr, MD, 2006

$\mathrm{F}$ ive years ago in an editorial to the Journal entitled "Robotic Cardiac Surgery: Quo Vadis?" I expressed serious doubts on the future application and general acceptance of this novel technology. These views were based on the high cost of the equipment itself, the added expenses of the individual procedures, the extended operating time, the bizarre concept of long-distance surgery, and, foremost, the question, What can robotics offer that other simpler and equally minimally invasive techniques cannot?

In a "counter-editorial," W. Randolph Chitwood, my good friend and fellow Carolinian, expressed a strong opposing view comparing my stance with that of Paget, who in 1897 prophesied the end of progress in cardiac surgery. The editor gave me the opportunity to respond, which was brief: Time will tell!

Randy, it looks like time told! Now, 4 years later, we have revisited the issue of the extent of application of robots in cardiac surgery. Unable to get the data any other way, we forwarded questionnaires in July of 2006 to all institutions in the United States that owned a da Vinci robot (Intuitive Surgical, Sunnyvale, Calif) concerning the yearly volume of robotic heart operations. We were able to obtain 260 responses (98.2\%) to 265 inquiries. On the basis of those responses, the following conclusions were drawn: 1) There was indeed an annual gradual increase in the number of da Vinci robots "operating" in the United States, with now approximately $25 \%$ of all cardiac surgical programs having da Vinci robots on their premises. 2) Despite this, however, the number of cardiac operations performed completely, or much more often partially, with the robotic technique showed only a modest yearly increase $(\sim 400)$, and the total is now approximately 1700 per year. This represents 7.3 operations per available robot and approximately $0.5 \%$ of all open procedures performed yearly in the United States, indicating that many of these machines are either idling or used for other purposes, primarily in urology. 3) The lion's share of procedures, more than half of cardiac procedures, are being done in a handful $(\sim 10)$ of institutions. The rest of the programs, which at one time or another did indeed perform robotic cardiac surgery, either ceased to do so or perform a few procedures per year. In 2005, of the "active" cardiac robotic programs, only $12 \%$ performed more than 50 robotic interventions yearly. Characteristically, in 2005, the average number of robotic cardiac procedures done in all but 1 of the 10 institutions that participated in the initial Food and Drug Administration approval process was a modest 14 cases yearly, with the single "outliner" program performing 60 valve repairs per year (Figures 1-4).

*See related editorials: Robicsek F. Robotic cardiac surgery: Quo vadis? J Thorac Cardiovasc Surg. 2003;126: 623-4. Chitwood WR Jr. An epistle to Dr. Robicsek. J Thorac Cardiovasc Surg. 2004;127:945-6. 


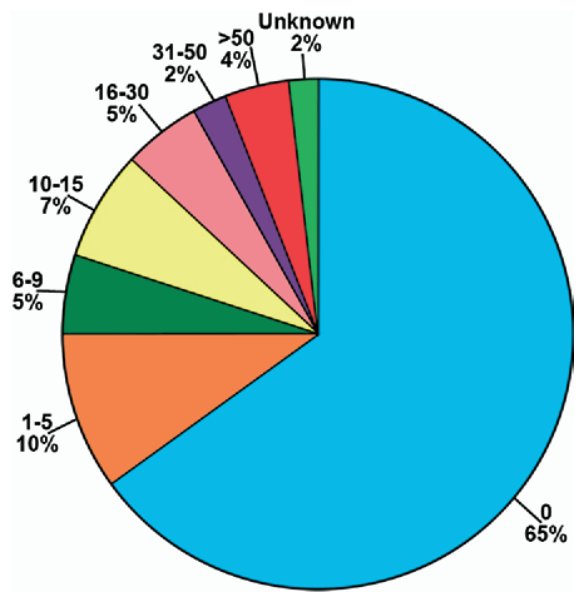

Figure 1. Cardiac caseload of institutions owning robots in the United States $(\mathbf{N}=\mathbf{2 6 5})$ in 2005.

Despite the above, there was a seldom-seen upsurge in lay-media publicity, as well as a plethora of scientific publications of robotic "firsts": robotic coronary surgery, robotic valve surgery, robotic pericardiectomy, robotic patent duct ligation, robotic lead placement, and so forth. During the last 6 years, more than 200 articles were published on the subject; approximately 1 article for every 25 robotic cardiac operations ever performed in the United States: 60 from the pen of a single author. My favorite article is written on robotic "myocardial laser revascularization," "2 which succeeded to combine the clinically dubious with the technically overcomplicated.

Because of the confusing terminology (eg, robotic, totally robotic, robotic assisted, hybrid-robotic), it was difficult to tell in some cardiac cases whether the technique applied was "totally" robotic, probably not more than $15 \%$

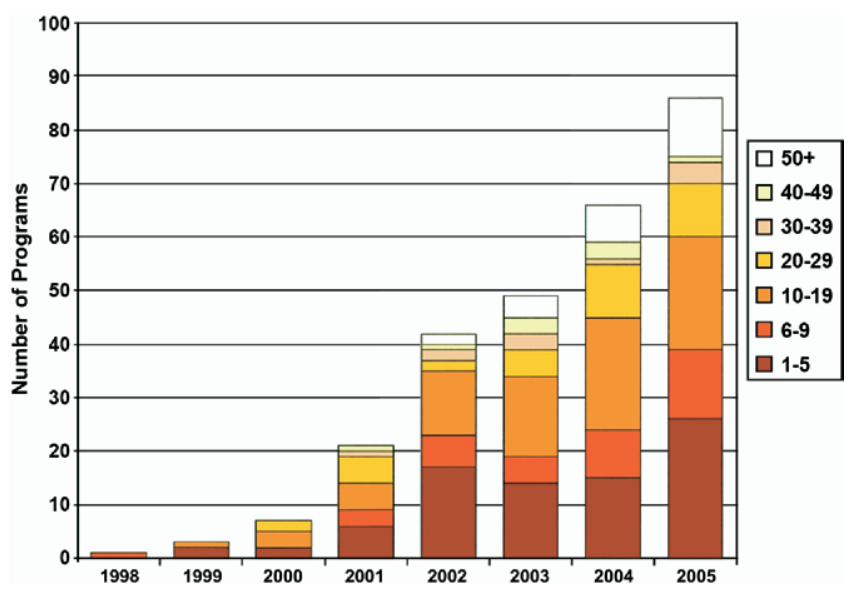

Figure 3. Program volume per year in active robotic cardiac surgery programs in the United States 1965-2005 (260 respondents to 265 surveys).

to $20 \%$. Most articles were case reports, with only a few addressing issues such as cost, learning curve, and late postoperative outcomes. Those few that did, however, came to the conclusion that robotic surgery takes longer and is considerably more expensive than conventional cardiac surgical interventions. ${ }^{3}$

Even if we disregard the $\$ 1.0$ to $\$ 1.5$ million purchase price for a single robot, there is also the $\$ 100$ to $\$ 140,000$ per year service agreement and the $\$ 1500$ to $\$ 2000$ cost for instruments and accessories per procedure. This increased expense could be only partially retrieved by the alleged modest improvement in the length of postoperative hospital stay. ${ }^{3}$ Notably, although a number of centers using roboticassisted technique reported good clinical outcomes, particularly in valve repair, ${ }^{4}$ the results, however, did not exceed

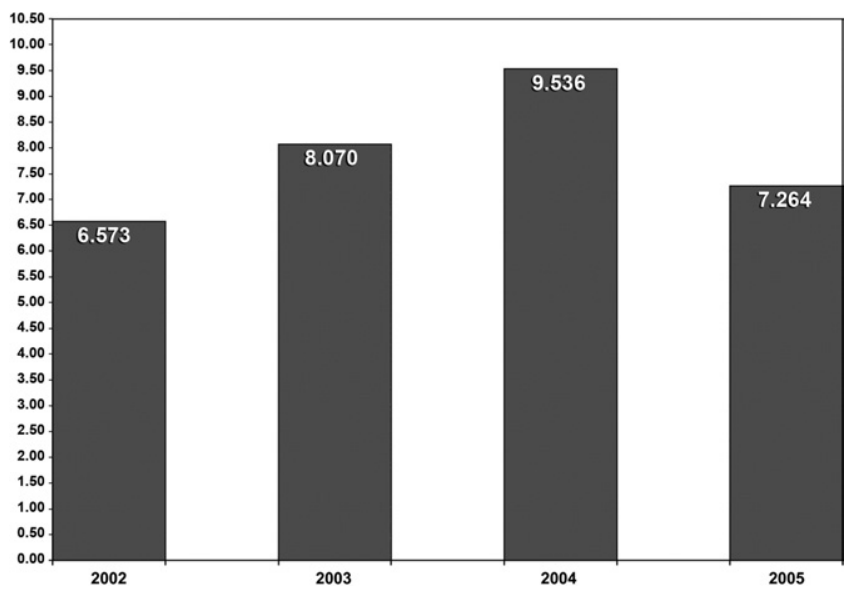

Figure 4. Robotic cardiac cases per robot in the United States 2002-2005 (260 respondents to 265 surveys).
Figure 2. Case load of programs with robots in active use for cardiac surgery ( $N=56$ ) in 2005 (260 respondents to 265 surveys).

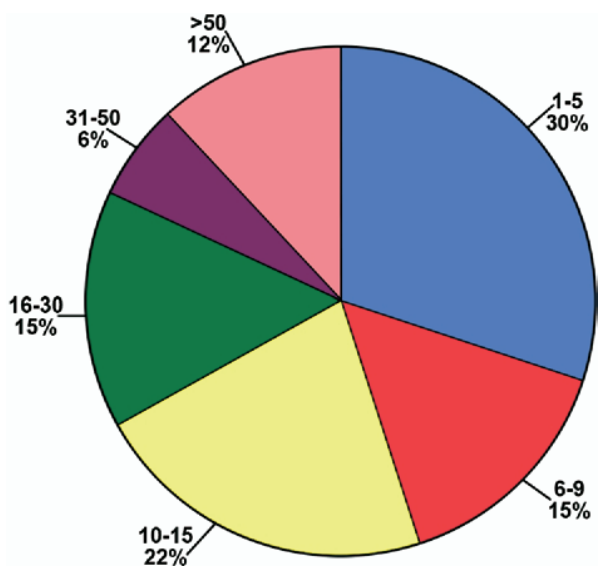

The Journal of Thoracic and Cardiovascular Surgery • February 2008 
those performed in centers of excellence ${ }^{5}$ using conventional, minimally invasive methods. Chitwood was as master surgeon before he had the robot, and he is a master surgeon with the robot as well. It is as simple as that!

The greatest disappointment in robotic cardiac surgery, however, is the issue of coronary interventions. We found only a scarce number of highly selected cases ${ }^{6}$ that were "totally robotic," and most of them were only "robot assisted," that is, conventional bypasses with robotic dissection of the thoracic artery. Typically, the latter took about twice as much time and cost than those done by conventional techniques. ${ }^{7}$

So, why didn't robotic cardiac surgery become popular? Although in the very beginning it generated a lot of enthusiasm and institutions virtually were "standing in line" to purchase robots, especially if the hospital on the other side of the town already had one, administrators soon realized that the robotic technique was too expensive and tied down operating room space for extended periods. Even after this extra expense and time were balanced versus the marketing aspects of attracting patients, especially those who needed mitral valve repair, the initial "robot-friendliness" of hospital administrators soon faded, just to resurge with the marketing success of robotic prostatectomies. The superiority of robotic prostatectomy over conventional techniques has been recently challenged as well. ${ }^{8}$

Today, cardiac surgeons, with the exception of a few "forever" enthusiasts such as Chitwood, seem to be less interested in robotic technology than they were 5 years ago. Robotic surgery imposes on the operator's time and on his time. The surgeon, who was able to do several major procedures per day using conventional methods, became weary of limiting himself or herself to a single robotic case, which takes extra hours to set up, extra hours to perform, and extra hours to disengage but provides no extra income. As it stands now, cardiac robotics seems to be an "overkill," reminiscent of the early times of coronary surgery when many surgeons performed anastomoses using operative microscopes. It was just too much.

If the future course of cardiac surgery tends toward the minimally invasive approach, robotics is minimally invasive indeed. To place issues in perspective, the virtues of robotics should be matched not only against conventional techniques (sternum-split) but also against varieties of minimally invasive techniques (eg, video-assisted, thoracoscopic). The skin incision will be the same length, the outcomes will be comparable, but costs and time spent are much higher in the "robotic" group. Also why does it have to be "tele"-robotic? In other words, why does anybody prefer such a grotesque situation? The operating room is fully set up for conventional surgery, the usual instruments are sterile and on the table, the nurse is gowned, a secondary surgeon is scrubbed and at the patient's side, and then an unseen manipulator "pulls the strings" from another room. The issue of "long-distance telerobotics" makes even less sense. Show me an institution that has a million-plus dollar robot but no cardiac surgeon on board? Buy the patient a plane ticket! ${ }^{9}$

The future of cardiac robotic surgery is uncertain. Logically, the next step in robotics should be preprogrammed interventions. These may indeed work to remove static brain lesions, but it is unlikely they will find application in the heart. Unlike in prostatic surgery, where robotic business is "booming," in open procedures where the viability of the heart has to be maintained during manipulation by cardiopulmonary bypass, a similar upsurge of robotics is highly unlikely. However, if both the industry and the surgeons would "reprogram" themselves to perfect small, patientside, high-technology manipulative arms, suitable to be used in conjunction with thoracoscopy, they would get rid of the huge teleconsole and the odd idea of "long-distance surgery." Elements of robotics could indeed be part of the future technology of minimally invasive cardiac inventions. The proper way, however, to proceed in this endeavor is not to flood the market with billions of dollars worth of hardware, most of it already obsolete, but to limit their use to a few centers with sincere professional interest, until in wellcontrolled trials, the technology proves itself economically sound as well as clinically superior to that which we already have today.

The author thanks Howell C. Sasser, PhD, for the statistical workup and Lisa Freeman for the technical conduction of the survey.

\section{Robotics \\ Very \\ fashionable \\ stance \\ Do your prostate \\ long-distance \\ But if you want \\ save a \\ life \\ Trust a surgeon \\ with a \\ knife}

Anonymous Hungarian Poet

\section{References}

1. Rodriguez E, Chitwood RW. Projecting developments in robotic cardiac surgery. The next 5 years. Am Heart Hosp J. 2006;4:183-5.

2. Brunsting III LA, Binford RS, Braly KC, Swan CR. Totally endoscope robot-assisted transmyocardial laser revascularization. Ann Thorac Surg. 2006;82:744-6.

3. Morgan JA, Thornton BA, Peacock JC, Hollingsworth KW, Smith CR, $\mathrm{Oz} \mathrm{MC}$, et al. Does robotic technology make minimally invasive cardiac surgery too expensive? A hospital cost analysis of robotic and conventional techniques. J Card Surg. 2005;20:246-51.

4. Chitwood WR. Current status of endoscopic and robotic mitral valve surgery. Ann Thorac Surg. 2005;79:S2248. 
5. Shoh AS, Hannish SA, Milano CA, Glower DD. Isolated mitral valve repair in patients with depressed left ventricular function. Ann Thorac Surg. 2005;80:1309-17.

6. Argenziano M, Katz M, Bonatti J, Srivastava S, Murphy D, Poirier $\mathrm{R}$, et al. and TECAB Trial Investigators. Results of the prospective multicenter trial of robotically assisted totally endoscopic coronary artery bypass grafting. Ann Thorac Surg. 2006;81: 1666-75.

7. Srivastava S, Gadasalli S, Agusala M, Kolluru R, Naidu J, Shroff M, et al. Use of bilateral internal thoracic arteries in CABG through lateral thoracotomy with robotic assistance in 150 patients. Ann Thorac Surg. 2006;81:800-6.

8. Su L-M. Laparoscopic outcomes similar to open prostatectomy, 9th International Meeting Endoneurological Society, Boston, 2006 ref. Surgical News, December 2006.

9. Micali S, Virgili G, Vannozri E, Grassi N, Jarrett TW, Bauer JJ, et al. Feasibility of telementoring between Baltimore (USA) and Rome (Italy): the first five cases. J Endourol. 2000;14:493-6. 